\title{
Reduced graphene oxide-poly(methyl methacrylate) nanocomposite as a supercapacitor
}

\author{
Zabiholah Zabihi, ${ }^{1}$ Paul Eduardo David Soto Rodriguez, ${ }^{2}$ Abderrahmane Boujakhrout, ${ }^{2}$ \\ Juan Carlos Viera, ${ }^{3}$ Jorge Alonso del Valle, ${ }^{3}$ Houshang Araghi $\quad{ }_{1}^{1}$ Reynaldo Villalonga ${ }^{2}$ \\ ${ }^{1}$ Department of Physics, Amirkabir University of Technology, Tehran, Iran \\ ${ }^{2}$ Department of Analytical Chemistry, Universidad Complutense de Madrid, Ciudad Universitaria s/n 28040, Madrid, Spain \\ ${ }^{3}$ Departament of Electrical and Electronic Engineering, University of Oviedo, Campus de Viesques, s/n, Edificio Departamental 3 \\ 33204, Gijón Asturias, Spain \\ Correspondence to: H. Araghi (E-mail: araghi@aut.ac.ir)
}

\section{INTRODUCTION}

Compared to traditional batteries used for energy storage applications, the so-called supercapacitors and ultracapacitors present superior properties in terms of power density, charge-discharge rates, and stability (long life-cycle performances) $)^{1-3}$ and have attracted attention in this field, especially for electrochemical energy storage devices. They are potential candidates to complement or eventually replace common batteries used in energy storage applications, such as for portable and wearable electronic devices and for electric and hybrid vehicles. ${ }^{4}$ The supercapacitors are classified according to their energy storage mechamism into two main categories: (1) electric double-layer capacitors (EDLCs) and (2) pseudocapacitors. ${ }^{5}$ In EDLCs, the capacitance originates from the accumulation of charges at the electrode-electrolyte interfaces. Therefore, controlling the specific surface area and pore size and enhancing electrical conductivity are the effective ways to achieve a high storage capacity. ${ }^{6}$ The second category is related to the energy storage of pseudocapacitance, where the storage mechanism occurs by transferring the faradic charges between electrolyte and electrode by reversible multielectron redox faradic reactions, producing higher specific capacitance and energy density than EDLCs. ${ }^{7-9}$ However, the poor electrical conductivity observed in pseudocapacitive electrodes can restrict the faradic reactions, therefore leading to unsatisfactory electrochemical performance and life cycles. To overcome this, several combinations of materials have been investigated to take advantage of their individual intrinsic properties; among these, the combination of metal oxide and graphene to improve electrochemical performance has been widely investigated. ${ }^{10,11}$ Instead, here the fabrication of an electrode based on a nonconductive polymer such as poly(methyl methacrylate) (PMMA; providing a large surface area) is investigated by studying how the electrical conductivity conferred by the conductive nanocomposites (graphene and metahybrid) and their inclusion act on the electrode electrochemical performance.

Three types of materials can be distinguished that are used in the fabrication of supercapacitor electrodes: carbon-based materials, ${ }^{12-17}$ transition metal oxides, ${ }^{18-27}$ and conductive polymers. ${ }^{28-30}$ Carbon-based materials are most frequently used for 
A)

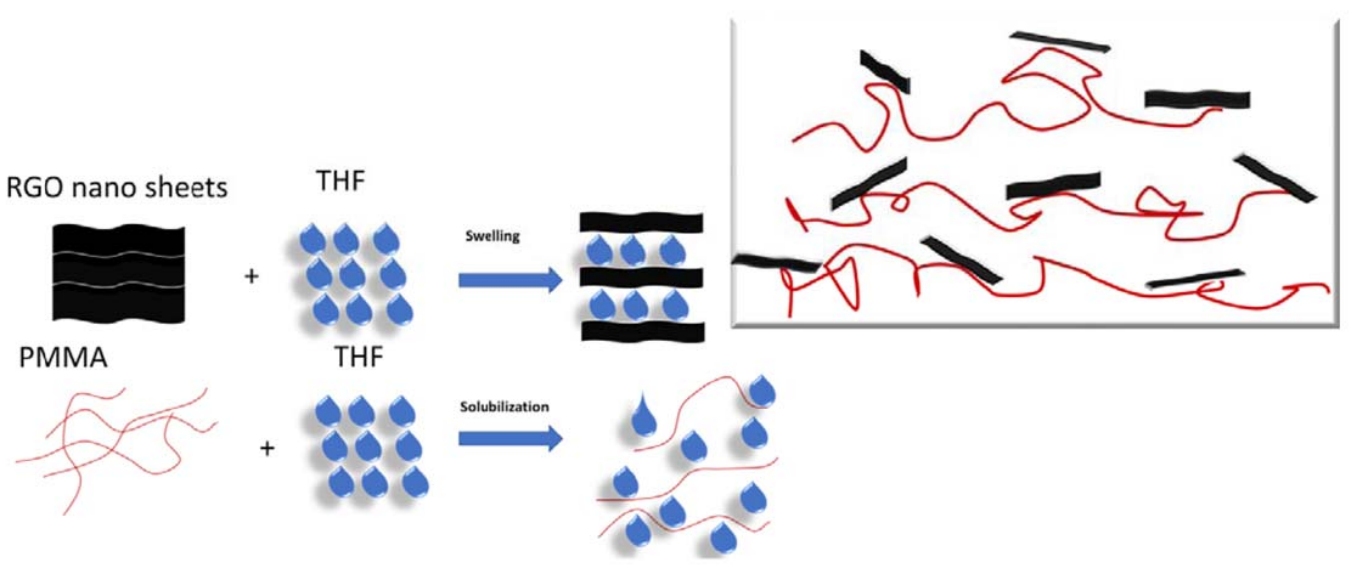

B)

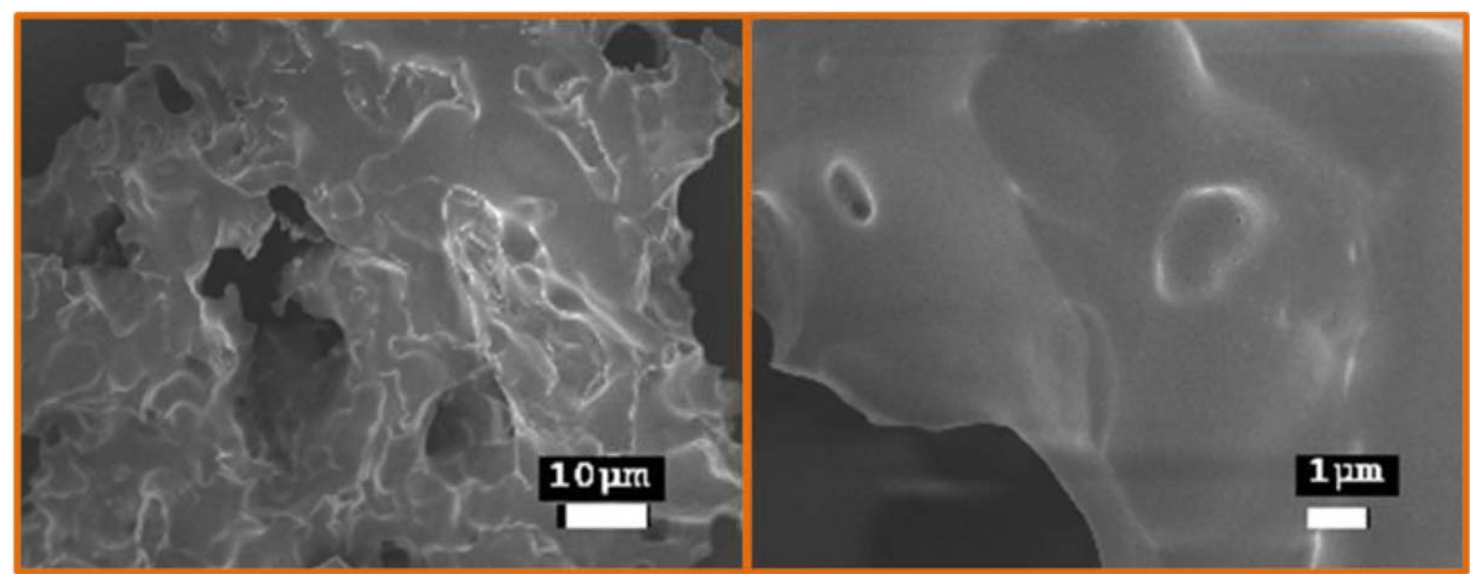

Figure 1. (A) Illustration of the RGO/PMMA synthesis process; (B) SEM image of 2\% RGO/PMMA. [Color figure can be viewed at wileyonlinelibrary.com]

electric double-layer capacitors, wherein the charge storage process is nonfaradic and the storage of energy is electrostatic. In particular, graphene-based materials are promising for energy storage applications because of their unique intrinsic properties: a highly tunable surface area, excellent electrical conductivity, high chemical stability, and superior mechanical behavior. Conductive polymers such as polyaniline (PANI), on the other hand, are shown to have more pseudocapacitor behavior like metal oxides. ${ }^{6}$

The rise of universal, wearable, portable, and flexible electronics comes with innovative demands for novel energy storage solutions. Due to the inherently flexible polymeric nature of conductive polymers, they have drawn a great deal of interest for flexible supercapacitor applications. ${ }^{31}$ Many material combinations, and on different length scales $(0 \mathrm{D}, 1 \mathrm{D}, 2 \mathrm{D}$, and 3D structures), have been the subject of study. The focus of this work is on graphene nanocomposites immersed in a nonconductive polymer matrix such as PMMA. Here, the nanocomposites used are reduced graphene oxide (RGO) and (3-Aminopropyl) triethoxysilane (APTES)-functionalized reduced graphene oxide (G) composites. As these nanocomposites are capable of conferring electrical conductivity to the matrix, we explore the effect of different percentage additions of nanocomposite and analyze their electrochemical behavior in different aqueous electrolytes: $\mathrm{KCl}, \mathrm{NaCl}, \mathrm{NaOH}$, and $\mathrm{H}_{2} \mathrm{SO}_{4}$. A faradic current is observed under slow scan rates for $\mathrm{RGO}$ with $\mathrm{NaOH}$ and $\mathrm{KCl}$ electrolytes, indicating significant electron charge transfer occurs in these electrolytes. In addition, for functionalized $\mathrm{RGO}$ in $\mathrm{KCl}$, an electrochemical double-layer capacitance is observed. This facile change from faradic to EDLC behavior upon nanocomposite functionalization, together with their low cost and beneficial mechanical properties (from the intrinsic flexible polymer nature), is extremely appealing for hybrid supercapacitor ensembles. Therefore, proposed electrodes are explored for their use as supercapacitors, and as such, an optimum nanocomposite filling percentage is found for which the highest faradic peak is measured and in which the highest energy is stored. The capacitance values obtained are compared to similar materials showing a good overall energy storage performance. For this comparison, similar systems were taken into consideration, that is, conductive materials in a nonconductive matrix.

All materials were prepared by wet chemical methods and characterized by means of scanning electron microscopy (SEM), differential scanning calorimetry (DSC), Fourier transform infrared (FTIR), cyclic voltammetry (CV), and electrochemical impedance spectroscopy (EIS). 


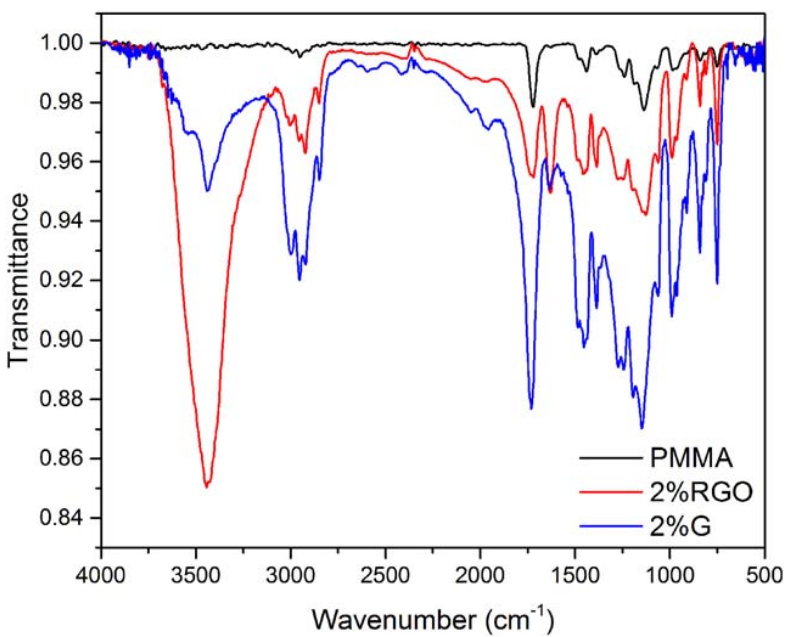

Figure 2. FTIR spectra of PMMA and 2 wt \% RGO/PMMA and 2 wt \% RGO/PMMA composites. [Color figure can be viewed at wileyonlinelibrary.com]

\section{EXPERIMENTAL}

\section{Preparation of Reduced Graphene Oxide}

The synthesis of the RGO suspension was realized according to the work presented by Park et al. ${ }^{32}$ For this, graphene oxide $(60 \mathrm{mg})$ was mixed with $20 \mathrm{~mL}$ of distilled water and sonicated in an ultrasound bath $(250 \mathrm{~W})$ for $2 \mathrm{~h}$ to obtain a homogenous GO suspension. For the final reduction, $180 \mathrm{~mL}$ of $N, N$-dimethylformamide (DMF) and $5 \mu \mathrm{L}$ of hydrazine monohydrate per $12 \mathrm{mg}$ of GO were added to the GO suspension and heated to $80^{\circ} \mathrm{C}$ for a period of $2 \mathrm{~h}$, yielding a black suspension that was thereafter sonicated for $5 \mathrm{~min}$. Several RGO suspensions with different reduction states were prepared. This was done by changing the volume of the reductant (hydrazine monohydrate). The RGO suspension was filtered and washed with ethanol (three times) to obtain a solid RGO.

\section{Preparation of RGO/PMMA Nanocomposites}

The RGO/PMMA nanocomposites were prepared by a solution intercalation method [a schematic is presented in Figure 1(A)]. A PMMA solution was prepared by dissolving PMMA powder in tetrahydrofuran (THF). The solid RGO solution was dissolved in THF at appropriate concentrations. Separately, both the RGO solution and PMMA solution were sonicated for $1 \mathrm{~h}$. Afterward, the RGO solution was added into the PMMA solution, and the mixture was stirred for $1 \mathrm{~h}$. A well-dispersed RGO/PMMA composite solution was then obtained. The final solution was poured under vigorous stirring into a beaker or jar filled with methanol. The precipitate was filtered and then washed with ethanol three times. The solid was dried in a vacuum for $12 \mathrm{~h}^{33}$

\section{Electrode Preparation and Measurements}

For the nanocomposite electrode, a $1 \mathrm{mg} / \mathrm{mL}$ solution of nanocomposite in ethanol was prepared, and of this $10 \mu \mathrm{l}$ was dropcast on the carbon working electrode $\left(0.1256 \mathrm{~cm}^{2}\right)$ of a threeelectrode screen-printed electrode (SPE; Orion High Technologies, Parla, Madrid, Spain, product OHT-000) and left to dry. All electrochemical (except the galvanostatic charge-discharge) measurements were done with a potentstioat (Autolab PGSTAT 302N, Metrohm Autolab, Utrecht, The Netherlands.).

\section{Galvanostatic Charge-Discharge Characterization}

To study the galvanostatic charge-discharge cycles, a Keithley SourceMeter (model 2440, Cleveland, $\mathrm{OH}$ ) was connected to the SPE, applying a fixed current of $5 \mu \mathrm{A}$, and simultaneously the potential was read out. LabVIEW (Laboratory Virtual Instrument Engineering Workbench), a software from National Instruments (Austin, TX) was set up to program the cycles. The potential limits were taken from the $\mathrm{CV}$ measurements in which the value for the reference potential was taken into account.

\section{RESULTS AND DISCUSSION}

\section{Morphological and Structural Characterization}

For the SEM images, a JEOL 7600 SEM (Tokyo, Japan) was used. The images were taken at $5 \mathrm{kV}$ and magnifications of $500 \times$ and $4000 \times$. The SEM images of $2 \%$ RGO/PMMA under both magnifications are shown in Figure 1(B). The film presents a large surface area, as expected for PMMA. Due to its low conductivity, a thin layer of gold was sputtered on top to enhance the contrast image.

Figure 2 shows the FTIR spectra of PMMA and the 2 wt \% RGO/ PMMA and 2 wt \% G/PMMA composites. FT-IR spectra were acquired with a Nicolet Nexus 670/870 spectrometer (Thermo Fisher

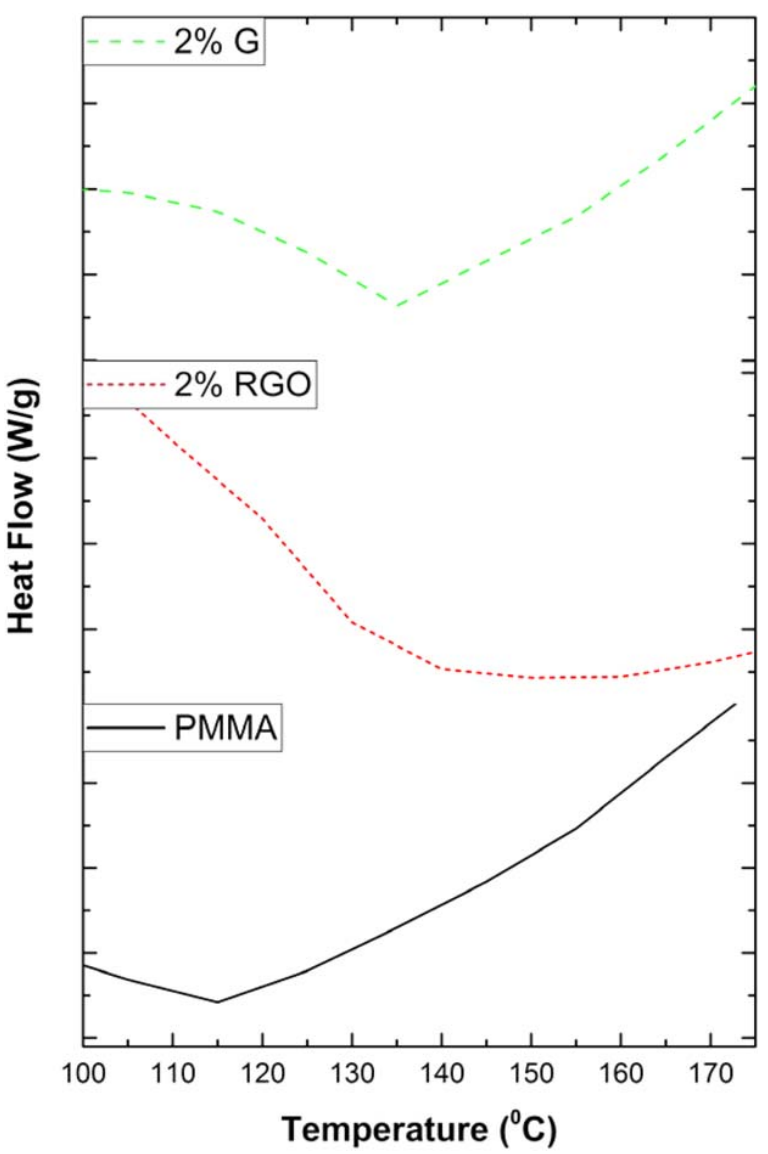

Figure 3. DSC thermograms of bare PMMA and PMMA with 2 wt $\%$ G or 2 wt $\%$ RGO recorded after second heating, at a heating rate of $10^{\circ} \mathrm{C} / \mathrm{min}$ in nitrogen atmosphere. [Color figure can be viewed at wileyonlinelibrary.com] 


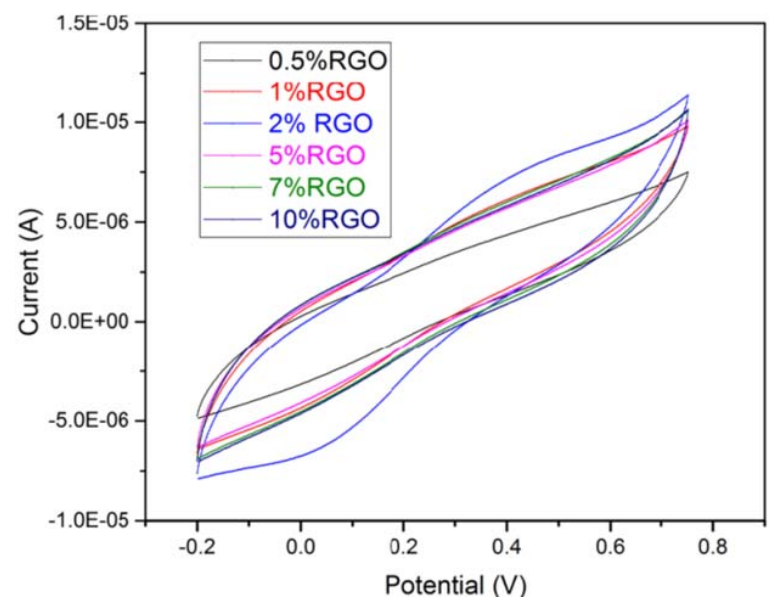

Figure 4. Different percentages of RGO nanocomposites in $1 \mathrm{M} \mathrm{KCl}$. [Color figure can be viewed at wileyonlinelibrary.com]

Scientific, Waltham, Massachusetts USA). For the bare PMMA, the spectrum showed characteristic bands at 2998, 1728, and $1143 \mathrm{~cm}^{-1}$, which correspond to the aliphatic $\mathrm{C}-\mathrm{H}, \mathrm{C}=\mathrm{O}$, and $\mathrm{C}-\mathrm{O}-\mathrm{C}$ groups, respectively. In contrast, the FTIR spectra from Figure 2 show that the inclusion of nanocomposite (2 wt \% RGO and $\mathrm{G}$ ) leads to representative peaks at 3442,1719 , and $1629 \mathrm{~cm}^{-1}$, which correspond to the $\mathrm{O}-\mathrm{H}, \mathrm{C}=\mathrm{O}$, and $\mathrm{C}=\mathrm{C}$ groups, respectively. (The peak at $2922 \mathrm{~cm}^{-1}$ corresponds to the $\mathrm{C}-\mathrm{H}$ groups. The bands between $1270 \mathrm{~cm}^{-1}$ and $990 \mathrm{~cm}^{-1}$ originate from the $\mathrm{C}-\mathrm{O}$ group.) This proves the presence of RGO and $\mathrm{G}$ in the PMMA.

In Figure 3 the DSC curves for bare PMMA and PMMA with 2 wt $\% \mathrm{G}$ and 2 wt \% RGO are presented. The glass-transition temperatures for PMMA and PMMA with 2 wt $\% \mathrm{G}$ and $2 \mathrm{wt}$ $\%$ RGO were determined to be 115,135 , and $140{ }^{\circ} \mathrm{C}$, respectively. These values are in agreement with that obtained in a previous experimental study. ${ }^{34}$

\section{Electrochemical Characterization}

Cyclic Voltammetry. To observe which electrochemical behavior dominates (i.e., which current dominates: faradic or capacitive), the electrodes were analyzed by cyclic voltammetry. The CV curve is shown in Figure 4 for a fixed scan rate of $150 \mathrm{mV} / \mathrm{s}$ and in a $1 \mathrm{M} \mathrm{KCl}$ electrolyte for the case of RGO at different concentrations. It shows a clear optimum value $(2 \%)$ at which both the redox-related cathodic and anodic peak currents are maximized. Even more, at higher concentrations it is constant. Therefore we consider the $2 \%$ nanocomposite filling as optimum; it presents a well-defined redox reaction (faradic peaks), suggesting a pseudocapacitance behavior.

Faradic peaks are an indication that electron transfers are occurring at the interface, though it generally depends on the electrolyte used. For this reason, different electrolytes were studied for the $2 \%$ RGO nanocomposite, and the results are shown in Figure 5. In comparison to $1 \mathrm{M} \mathrm{KCl}$ electrolyte, the RGO nanocomposite/ PMMA electrode (CV curves with different scan rates are presented in Figure $\mathrm{S} 1$ in the Supporting Information) did not show a faradic reaction in the $0.1 \mathrm{M} \mathrm{KCl}$ nor in the $0.1 \mathrm{M} \mathrm{H}_{2} \mathrm{SO}_{4}$; although a small reduction peak appears, it disappears at higher scan rates
(Figure S2). However, for $\mathrm{NaOH}$, clear oxidation and reduction current peaks are observed, indicating that faradic currents are present. In addition, the results for $2 \% \mathrm{G}$ are shown. In contrast to the RGO in the $0.1 \mathrm{M} \mathrm{KCl}$ electrolyte, the $\mathrm{CV}$ curve is more square, as would be expected for an EDLC, and also the overall current increases compared to the $\mathrm{RGO}$ case, which leads to a higher capacitance $(2.23 \mathrm{~F} / \mathrm{g})$. For $0.1 \mathrm{M} \mathrm{H}_{2} \mathrm{SO}_{4}$, the $\mathrm{CV}$ curve shows neither an evident faradic current peak nor a square-like shape, and in $0.1 \mathrm{M} \mathrm{NaOH}$ only small prominent faradic peaks appear.

These observations indicate that $G$ exhibits EDLC behavior in $\mathrm{KCl}$ electrolyte and RGO pseudocapacitance at $1 \mathrm{M} \mathrm{KCl}$ but not at $0.1 \mathrm{M}$, indicating that for this concentration the number of ions transferring charge to the electrode is too small to be measurable. Nevertheless, for the $0.1 \mathrm{M} \mathrm{NaOH}$ concentration, pseudocapacitance is clearly present, indicating that the related ion transfer is more effective. This fact might be related to a faster adherence of the ions to the electrode surface. In order to see if the cation $\mathrm{Na}^{+}$or the anion $\mathrm{OH}^{-}$is responsible for the observed feature, the RGO/PMMA electrode was tested in $0.1 \mathrm{M} \mathrm{NaCl} \mathrm{elec-}$ trolyte (see the Supporting Information), for which no faradic peaks were present, thus strongly suggesting that the $\mathrm{OH}^{-}$anions are responsible for the observed pseudocapacitance.

As seen in the SEM images (Figure 1), the RGO/PMMA electrode film is not smooth, and therefore the accessibility of the ions toward the electroactive spots at the electrode surface (mainly by mass transport) will be dictated by the scan rate at which the CV measurements are performed, and hence the capacitance will change accordingly. The area of the CV curve represents the charge, being therefore proportional to the capacitance. Therefore, a variation in area of the CV curve is expected to be observed when the capacitance changes. Indeed, as can be seen from Figure 6, in which the CV curves at different scan rates for both $2 \% \mathrm{G}$ and $2 \%$ RGO are shown, a more square-like shape (increasing area) for the case of $G$ upon an increase in scan rate is seen, and an increase of the faradic current peaks (increasing area) for the case of RGO is observed.

The capacitance $C$ is determined from the CV curves at different scan rates according to eq. $(1)^{35}$ and is presented in Table 1 together with capacitance values of similar systems (conductive elements in a nonconductive matrix) obtained in other works:

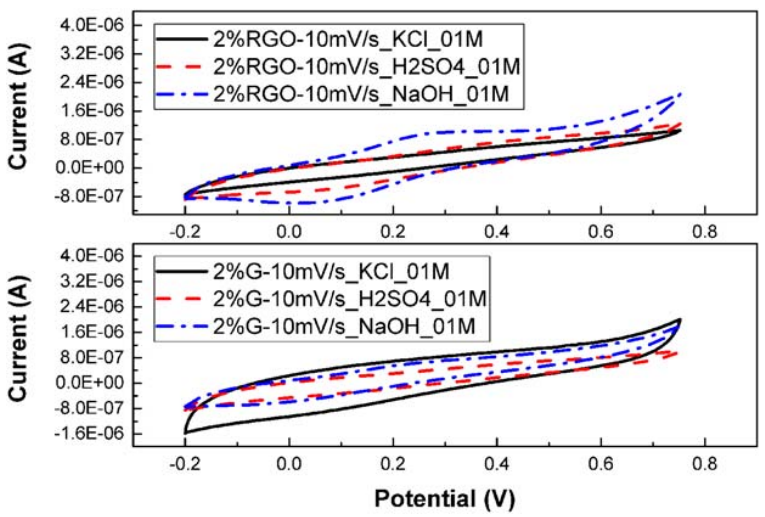

Figure 5. Different electrolytes $\mathrm{KCl}, \mathrm{H}_{2} \mathrm{SO}_{4}$, and $\mathrm{NaOH}$ for both $2 \% \mathrm{RGO}$ (top) and $2 \% \mathrm{G}$ (bottom) nanocomposites. [Color figure can be viewed at wileyonlinelibrary.com] 


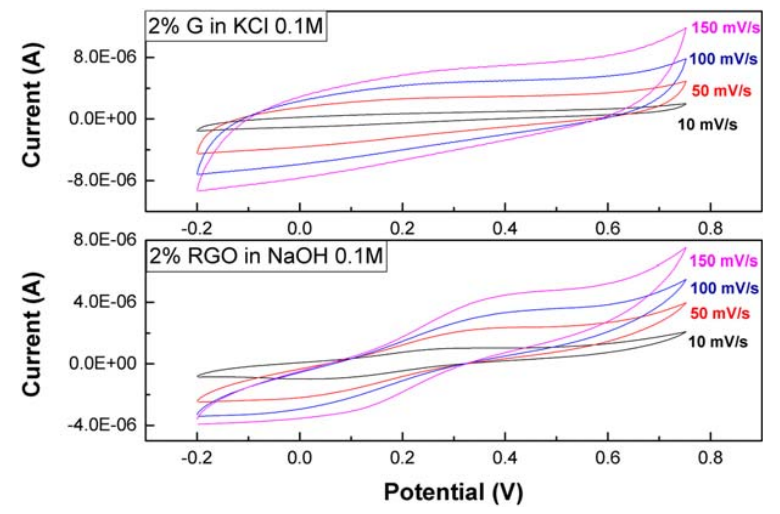

Figure 6. $\mathrm{CV}$ curves for $2 \% \mathrm{G}$ in $0.1 \mathrm{M} \mathrm{KCl}$ (top) and 2\% RGO in $0.1 \mathrm{M}$ $\mathrm{NaOH}$ (bottom). [Color figure can be viewed at wileyonlinelibrary.com]

$$
C=\frac{I_{\text {ave }}}{m \times s}
$$

where $I_{\text {ave }}$ is the current, $s$ is the scan rate, and $m$ is the mass of deposited material $(\sim 1 \mathrm{mg} / \mathrm{mL})$.

Electrochemical Impedance Spectroscopy. In order to assess the ionic conductivity, a fast redox probe such as ferro/ferricyanide was used in a $1 \mathrm{M} \mathrm{KCl}$ electrolyte (for which the RGO showed pseudocapacitance and G an EDLC behavior). The corresponding Nyquist plot is shown in Figure 7. In the ideal case for a pure capacitor, the corresponding impedance response corresponds to a straight line being parallel to the imaginary axis of the Nyquist plot. However, in real capacitors, a high slope indicating a steeply rising capacitive impedance response is observed in the lowfrequency region together with high-frequency semicircular features related to the bulk and interfacial properties. The increased

Table 1. Comparison of Specific Capacitance of PMMA Composite Electrodes to Other Electrodes

\begin{tabular}{|c|c|c|c|}
\hline Material & Electrolyte & $\begin{array}{l}\text { Specific capacitance } \\
\text { (SC) (F/g) }\end{array}$ & Reference \\
\hline $\mathrm{Fe}_{3} \mathrm{O}_{4}$ electrode & $1.0 \mathrm{M} \mathrm{KOH}$ & 3 & 36 \\
\hline Perovskite $\mathrm{SrRuO}_{3}$ & $6 \mathrm{M} \mathrm{KOH}$ & 8 & 37 \\
\hline $\mathrm{RuO}_{2}$ & $6 \mathrm{M} \mathrm{KOH}$ & 20 & 37 \\
\hline $\mathrm{La}_{0.2} \mathrm{Sr}_{0.8} \mathrm{RuO}_{3}$ & $6 \mathrm{M} \mathrm{KOH}$ & 21 & 38 \\
\hline Sb-doped $\mathrm{SnO}_{2}$ nanocrystallite thin film & $1 \mathrm{M} \mathrm{KOH}$ & 16 & 38 \\
\hline Indium oxide $\left(\mathrm{In}_{2} \mathrm{O}_{3}\right)$ nanospheres & $1 \mathrm{M} \mathrm{Na}_{2} \mathrm{SO}_{4}$ & 7.6 & 39 \\
\hline Carbon fibers (CF) & $3 \mathrm{M} \mathrm{KCl}$ & 0.06 & 40 \\
\hline Activated carbon fiber (ACF) & $3 \mathrm{M} \mathrm{KCl}$ & 2.63 & 40 \\
\hline Industrially activated carbon fiber (IACF) & $3 \mathrm{M} \mathrm{KCl}$ & 0.1 & 40 \\
\hline CF/PAN & PC/EC+0.1 M LiTFSI & 0.003 & 40 \\
\hline ACF/PAN & PC/EC+0.1 M LiTFSI & 0.055 & 40 \\
\hline IACF/PAN & PC/EC+0.1 M LiTFSI & 0.026 & 40 \\
\hline CF/PEGDGE ${ }^{a}$ & $0.1 \mathrm{M}$ LiTFSI & 0.0045 & 40 \\
\hline ACF/PEGDGE & $0.1 \mathrm{M}$ LiTFSI & 0.0014 & 40 \\
\hline CF/PEGDGE & $0.1 \mathrm{M}$ LiTFSI + IL & 0.0111 & 40 \\
\hline ACF/PEGDGE & $0.1 \mathrm{M} \mathrm{LiTFSI}+$ IL & 0.0522 & 40 \\
\hline CFs by chemical activation with $\mathrm{KOH}$ & $3 \mathrm{M} \mathrm{KCl}$ & 3.27 & 41 \\
\hline $\mathrm{CF}^{+}$carbon nanotubes & $3 \mathrm{M} \mathrm{KCL}$ & 2.63 & 42 \\
\hline $\mathrm{CF}^{+}$carbon aerogels & $3 \mathrm{M} \mathrm{KCL}$ & 14 & 42 \\
\hline CNT fiber & Ionic liquid electrolyte & $20-24$ & 43 \\
\hline Graphene & $0.5 \mathrm{~N} \mathrm{H}_{2} \mathrm{SO}_{4}$ & 14 & 44 \\
\hline As-received CF & $3 \mathrm{M} \mathrm{KCl}$ & $0.06(0.01)$ & 45 \\
\hline $\mathrm{CAG}^{\mathrm{b}}$-modified (pressing) (CF +22 wt \% CAG) & $3 \mathrm{M} \mathrm{KCl}$ & $14.3(0.2)$ & 45 \\
\hline CAG-modified (infusion) (CF + 15.9 wt \% CAG) & $3 \mathrm{M} \mathrm{KCl}$ & $8.7(0.3)$ & 45 \\
\hline CAG-modified (infusion scaled up) (CF + 9.5 wt \% CAG) & $3 \mathrm{M} \mathrm{KCl}$ & $5.9(0.4)$ & 45 \\
\hline CNT+PANI & $1 \mathrm{M} \mathrm{H}_{2} \mathrm{SO}_{4}$ & 16 & 46 \\
\hline 2\%RGO/PMMA & $1 \mathrm{M} \mathrm{KCl}$ & 24.8 & This work \\
\hline 2\%RGO/PMMA & $1 \mathrm{M} \mathrm{NaOH}$ & 30.4 & This work \\
\hline 2\%G/PMMA & $1 \mathrm{M} \mathrm{KCl}$ & 15.08 & This work \\
\hline 2\%G/PMMA & $1 \mathrm{M} \mathrm{NaOH}$ & 25.6 & This work \\
\hline
\end{tabular}

a Poly(ethylene glycol) diglycidyl ether (PEGDGE)

${ }^{\mathrm{b}}$ Carbon aerogel (CAG) 


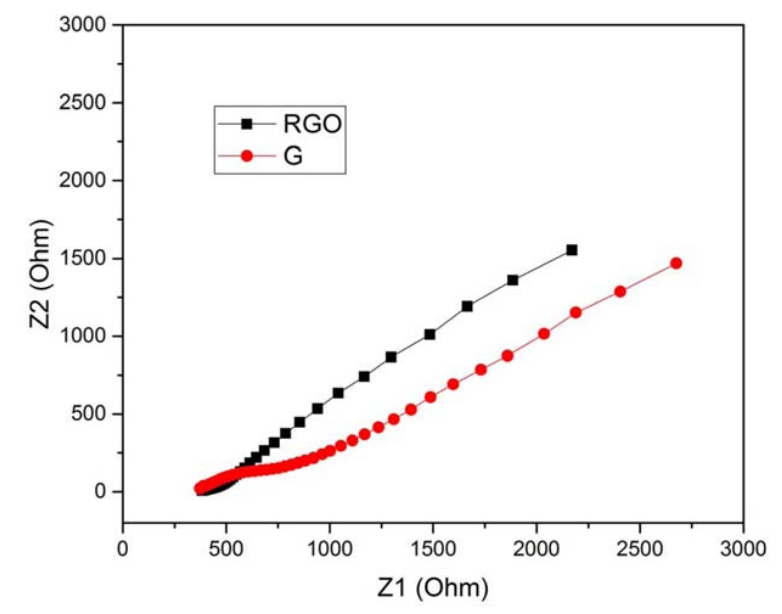

Figure 7. Nyquist plot for both 2\% RGO (black curve) and 2\% G (red curve). [Color figure can be viewed at wileyonlinelibrary.com]

semicircle observed in $\mathrm{G}$ indicates an increase in ionic resistance for $\mathrm{G}$ (red curve) over RGO. The steeper (higher slope) for RGO indicates a faster redox mechanism compared to that for G.

The corresponding plot of resistance versus nanocomposite weight percentage is shown in Figure 8. An inflection point close to $2 \%$ is observed for both nanocomposites, which also corresponds to the optimized weight percentage observed for the pseudocapacitance in $1 \mathrm{M} \mathrm{KCl}$.

Electron Transport Model. A strong RGO-dependent behavior from the Nyquist plots is observed; see Figure 8. The addition of RGO in the composites results in a corresponding reduction in the size of the impedance planar plots, and it gradually decreases with increasing RGO concentration up to the incorporation of $2 \%$ RGO and then starts increasing. At low weight percentages, the average separation distance between RGO sheets is large. Thus, the electron transport paths are not formed within the PMMA matrixes. Therefore, the overall electrical conductivity of RGO/PMMA composites takes the values

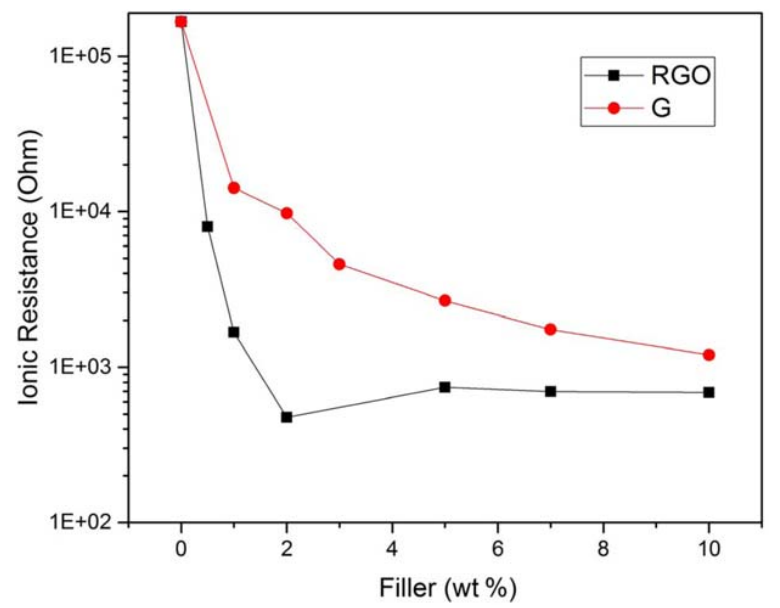

Figure 8. Ionic resistance, obtained from their corresponding Nyquist plots, for both RGO and G depending on the nanocomposite weight percentage. [Color figure can be viewed at wileyonlinelibrary.com] of the PMMA matrix. When the weight percentage of nanofillers exceeds the critical weight percentage (percolation threshold), the electrical conductivity of RGO/PMMA composites increases by several orders of magnitude and, finally, will tend to be constant (percolation process). A quantum tunneling mechanism plays a dominant role in electrical transport in graphene-based composites. Simmons ${ }^{48}$ derived a formula for the electrical tunneling effect between two electrodes separated by a thin insulating film (as electrodes we may consider on one side the electrolyte and at the other the carbon electrode sandwiching the PMMA nanocomposite thin film), and the tunnelingtype contact resistances can be expressed as

$$
I=\frac{2 e}{h} \int_{0}^{\infty} T(E) M(E)[f(E-e V)-f(E)] d E
$$

Here, Planck's constant is shown by $h, e$ is electron charge, the symbol $M(E)$ denotes the total number of conduction channels, $T(E)$ is a transmission probability, and $f(E)$ is the Fermi-Dirac distribution function. Approximating asymptotically eq. (2) by means of the Sommerfeld expansion and considering a low bias voltage $V$, we find the resistance can be written as follows:

$$
R=\frac{V}{I}=\frac{h}{2 e^{2}} \times \frac{1}{M T}
$$

By solving the Schrodinger equation for a polymer potential barrier with the Wentzel-Kramers-Brillouin (WKB) approximation, ${ }^{47}$ it is possible to relate the transmission probability $T$ of the electron, which gives the probability of an electron tunneling through the polymer potential barrier present between graphene layers, and the minimum distance between two neighboring graphene layers $(d)$ and the height of the barrier $\left(\varphi_{\text {eff }}\right)^{48,49}$ :

$$
T=\exp \left(-\frac{2 \pi d}{h} \sqrt{8 m_{e} \varphi_{\text {eff }}}\right)
$$

where

$$
\begin{gathered}
\varphi_{\mathrm{eff}}=\varphi_{0}-\left(\frac{V}{2 d}\right)\left(s_{1}+s_{2}\right)-\left[\frac{5.75}{K\left(s_{1}-s_{2}\right)}\right] \ln \left[\frac{s_{2}\left(d-s_{1}\right)}{s_{1}\left(d-s_{2}\right)}\right] \\
s_{1}=\frac{6}{K \varphi_{0}} \\
s_{2}=d\left[1-\frac{46}{3 \varphi_{0} K d+20-2 V K d}\right]
\end{gathered}
$$

and $m_{e}$ is the electron mass. By combining eqs. (3) and (4), we may determine the shortest distance between two graphene layers:

$$
d=\frac{h}{2 \pi \sqrt{8 m_{e} \varphi_{\text {eff }}}} \ln \left(\frac{2 e^{2}}{h} M R\right)
$$

The present model can describe the effect observed in Figure 8, where it is shown that as the nanofiller content increases, the resistance of the composite decreases. More specifically, this can be explained by eq. (8), which shows that as the minimum distance between graphene layers decreases, it becomes easier to construct a conductivity network [as the distance $d$ is proportional to $\ln (M R)]$.

Stability. In $1 \mathrm{M} \mathrm{KCl}$, stable charge-discharge cycles at constant current $(5 \mu \mathrm{A})$ were obtained and remained stable even over 900 

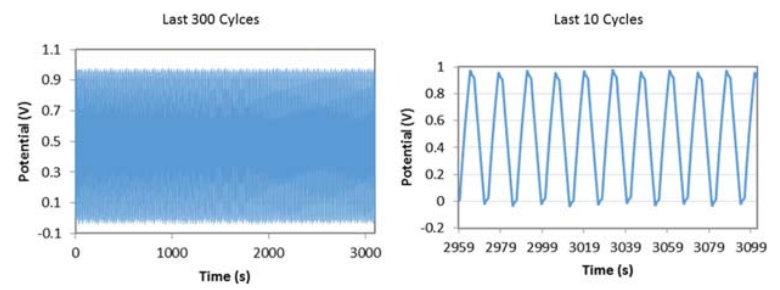

Figure 9. Last 300 and last 10 charge-discharge cycles at a constant current of $5 \mu \mathrm{A}$ just after 900 cycles. [Color figure can be viewed at wileyonlinelibrary.com]

cycles. As an example, Figure 9 shows the last 300 and the last 10 cycles for the $2 \%$ RGO/PMMA supercapacitor. The tests were carried out using a Keithley 2440 SourceMeter. The resulting capacitances calculated from these cycles are in accordance with the values obtained by the CV measurements. The capacitance can be calculated by the following equation:

$$
C=\frac{I_{\mathrm{dis}} \times \Delta t_{\mathrm{dis}}}{\Delta V_{\mathrm{dis}}}
$$

where $I_{\mathrm{dis}}$ corresponds to the discharge current, $\Delta t_{\mathrm{dis}}$ is the discharge time, and $\Delta V_{\mathrm{dis}}$ is the maximum potential reached minus the ohmic drop.

\section{CONCLUSIONS}

An optimized filler weight percentage of $2 \%$ was observed for which pseudocapacitance was obtained for RGO in a $1 \mathrm{M} \mathrm{KCl}$ electrolyte and around which the inflection point of ionic resistance versus filler weight percentage was observed. Instead of pseudocapacitance, electrostatic electron transport (EDLC) is observed for functionalized RGO $(G)$ in $0.1 \mathrm{M} \mathrm{NaOH}$. The inclusion of RGO in the PMMA is equivalent, in an electrochemical manner, to a common conductive polymer such as PAN. A simple electron transport model is presented that explains the observed electronic measurements. In addition, we have determined that the RGO/PMMA conductive polymer has higher affinity toward $\mathrm{OH}^{-}(r=133 \mathrm{pm})$ anions than the other anions studied, both $\mathrm{Cl}^{-}(r=167 \mathrm{pm})$ and $\mathrm{SO}_{4}^{-}(r=258 \mathrm{pm})$, being thus related to an increased transport due to the smaller anion size. In this sense, the observed pseudocapacitance is no surprise as conductive polymers such as PANI show similar behavior. On the other hand, the observed EDLC for G must be directly related to the APTES functionalization, which changes the electrode surface functional groups, facilitating the electrochemical double-layer formation, and therefore the electrostatic charge transfer dominates over the observed redox reaction of the nonfunctionalized RGO nanocomposite. For the latter, stable (over 900 cycles) charge-discharge cycles have been observed, confirming their promising performance.

These results show that a low-cost nanocomposite PMMA supercapacitor can be easily fabricated, which opens the possibility to fabricate a hybrid supercapacitor combining electrodes based on RGO and functionalized G. In addition, these materials would be excellent candidates to be analyzed with a solid PMMA electrolyte to have an all-polymer supercapacitor, which in principle would allow a higher power as $P=I V^{2}$, so the potential window could be increased even further as compared to when an aqueous electrolyte is used (as here electrolysis is the limitation). Also, it would permit fabrication of a highly flexible supercapacitor.

\section{ACKNOWLEDGMENTS}

Zabiholah Zabihi is grateful to the Department of Analytical Chemistry at Universidad Complutense de Madrid for hospitality during a nine-month visit, where the experimental part of this work was carried out. He is grateful to the Iran Ministry of Science, Research, and Technology for a fellowship in support of this visit. This work was supported in part by the Science and Innovation Spanish Ministry and FEDER under the projects DPI2013-046541R, TIN2014-56967-R, and TEC2016-80700-R (AEI/FEDER, UE), and by the Principality of Asturias Government under project FC15-GRUPIN14-073. P.E.D.S.R. and R.V. acknowledge the Spanish Ministry of Economy and Competitiveness (grants CTQ201458989-P and CTQ2015-71936-REDT).

\section{REFERENCES}

1. Miller, J. R.; Simon, P. Science 2008, 321, 651.

2. Simon, P.; Gogotsi, Y. Nat. Mater. 2008, 7, 845.

3. Liu, C.; Li, F.; Ma, L. P.; Cheng, H. M. Adv. Mater. 2010, 22, E28.

4. Kaempgen, M.; Chan, C. K.; Ma, J.; Cui, Y.; Gruner, G. Nano Lett. 2009, 9, 1872.

5. Winter, M.; Brodd, R. J. Chem. Rev. 2004, 104, 4245.

6. Shi, W.; Zhu, J.; Sim, D. H.; Tay, H. H.; Lu, Z.; Zhang, X.; Sharma, Y.; Srinivasan, M.; Zhang, H.; Hng, H. H.; Yan, Q. J. Mater. Chem. 2011, 21, 3422.

7. Hu, C. C.; Chang, K. H.; Lin, M. C.; Wu, Y. T. Nano Lett. 2006, 6, 2690.

8. Ke, Y. K.; Tsai, Y. S.; Huang, Y. S. J. Mater. Chem. 2005, 15, 2122.

9. Xiao, W.; Xia, H.; Fuh, J. Y. H.; Lu, L. J. Power Sources 2009, 193, 935.

10. Abouimrane, A.; Compton, O. C.; Amine, K.; Nguyen, S. T. J. Phys. Chem. C 2010, 114, 12800.

11. Yan, J.; Fan, Z. J.; Wei, T.; Qian, W. Z.; Zhang, M. L.; Wei, F. Carbon 2010, 48, 3825.

12. Xia, K. S.; Gao, Q. M.; Jiang, J. H.; Hu, J. Carbon 2008, 46, 1718.

13. Frackowiak, E. Phys. Chem. Chem. Phys. 2007, 9, 1774.

14. Frackowiak, E.; Metenier, K.; Bertagna, V.; Beguin, F. Appl. Phys. Lett. 2000, 77, 2421.

15. Du, C. S.; Pan, N. Nanotechnology 2006, 17, 5314.

16. Zhang, L. L.; Zhao, X. S. Chem. Soc. Rev. 2009, 38, 2520.

17. Zhu, J. X.; Sun, T.; Hng, H. H.; Ma, J.; Boey, F. Y. C.; Lou, X. W.; Zhang, H.; Xue, C.; Chen, H. Y.; Yan, Q. Y. Chem. Mater. 2009, 21, 3848.

18. Wu, N. L. Mater. Chem. Phys. 2002, 75, 6.

19. Cottineau, T.; Toupin, M.; Delahaye, T.; Brousse, T.; Belanger, D. Appl. Phys. A: Mater. Sci. Process. 2006, 82, 599.

20. Jiang, J. H.; Kucernak, A. Electrochim. Acta 2002, 47, 2381.

21. Toupin, M.; Brousse, T.; Belanger, D. Chem. Mater. 2004, 16, 3184. 
22. Roberts, A. J.; Slade, R. C. T. J. Mater. Chem. 2010, 20, 3221.

23. Hu, C.-C.; Chang, K.-H.; Lin, M.-C.; Wu, Y.-T. Nano Lett. 2006, 6, 2690.

24. Li, G.-R.; Feng, Z.-P.; Ou, Y.-N.; Wu, D.; Fu, R.; Tong, Y.-X. Langmuir 2010, 26, 2209.

25. Yuan, G. H.; Jiang, Z. H.; Aramata, A.; Gao, Y. Z. Carbon 2005, 43, 2913.

26. Gujar, T. P.; Shinde, V. R.; Lokhande, C. D.; Kim, W. Y.; Jung, K. D.; Joo, O. S. Electrochem. Commun. 2007, 9, 504.

27. Selvan, R. K.; Perelshtein, I.; Perkas, N.; Gedanken, A. J. Phys. Chem. C 2008, 112, 1825.

28. Wang, K.; Huang, J.; Wei, Z. J. Phys. Chem. C 2010, 114, 8062.

29. Ryu, K. S.; Kim, K. M.; Park, N. G.; Park, Y. J.; Chang, S. H. J. Power Sources 2002, 103, 305.

30. Mastragostino, M.; Arbizzani, C.; Soavi, F. J. Power Sources 2001, 97-98, 812.

31. Lehtimäki, S.; Suominen, M.; Damlin, P.; Tuukkanen, S.; Kvarnströ, C.; Lupo, D. ACS Appl. Mater. Interfaces 2015, 7 (40), 22137.

32. Park, S.; An, J.; Jung, I.; Piner, R. D.; An, S. J.; Li, X.; Velamakanni, A.; Ruoff, R. Nano Lett. 2009, 9, 1593.

33. Zeng, X.; Yang, J.; Yuan, W. Eur. Polym. J. 2012, 48, 1674.

34. Pham, V. H.; Dang, T. T.; Hur, S. H.; Kim, E. J.; Chung, J. S. ACS Appl. Mater. Interfaces 2012, 4, 2630.

35. Conway, B. E. Electrochemical Supercapacitors: Scientific Fundamentals and Technological Applications; Springer: New York, 1999.
36. Wang, S. Y.; Ho, K. C.; Kuo, S. L.; Wu, N. L. J. Electrochem. Soc. 2006, 153, A75.

37. Wohlfahrt-Mehrens, M.; Schenk, J.; Wilde, P. M.; Abdelmula, E.; Axmann, P.; Garche, J. J. Power Sources 2002, 105, 182.

38. Wu, N. L. Mater. Chem. Phys. 2002, 75, 6.

39. Chang, J.; Lee, W.; Mane, R. S.; Cho, B. W.; Han, S. H. Electrochem. Solid-State Lett. 2008, 11, A9.

40. Shirshova, N.; Qian, H.; Shaffer, M. S. P.; Steinke, J. H. G.; Greenhalgh, E. S.; Curtis, P. T.; Kucernak, A.; Bismarck, A. Composites, Part A 2013, 46, 96.

41. Qian, H.; Diao, H.; Shirshova, N.; Greenhalgh, E. S.; Steinke, J. G. H.; Shaffer, M. S. P.; Bismarck, A. J. Colloid Interface Sci. 2013, 395, 241.

42. Shirshova, N.; Qian, H.; Houllé, M.; Steinke, J. H. G.; Kucernak, A. R. J.; Fontana, Q. P. V.; Greenhalgh, E. S.; Bismarck, A.; Shaffer, M. S. P. Faraday Discuss. 2014, 44, 81.

43. Senokos, E.; Reguero, V.; Palma, J.; Vilatela, J. J.; Marcilla, R. Nanoscale 2016, 8, 3620.

44. Si, Y.; Samulski, E. T. Chem. Mater. 2008, 20, 6792.

45. Qian, H.; Kucernak, A. R.; Greenhalgh, E. S.; Bismarck, A.; Shaffer, M. S. P. ACS Appl. Mater. Interfaces 2013, 5(13), 6113.

46. Liu, Q.; Nayfeh, M. H.; Yau, S. T. J. Power Sources 2010, 195,7480

47. Bohm, D. Quantum Theory; Dover: New York, 1989.

48. Simmons, J. G. J. Appl. Phys. 1963, 34, 1793.

49. Zabihi, Z.; Araghi, H. Synth. Metals 2016, 217, 87. 